\title{
Ludwik Fleck (1896-1961) e a translação do conhecimento: considerações sobre a genealogia de um conceito
}

\author{
Ludwik Fleck (1896-1961) and knowledge translation: considerations \\ about the genealogy of a concept
}

Leticia Barbosa', André Pereira Neto ${ }^{2}$

RESUMO A racionalidade científica moderna tem sido questionada, nos últimos anos, de diversas maneiras, entre as quais destaca-se a translação do conhecimento - um método de pesquisa e ação que visa a incentivar a troca entre diferentes saberes, construindo um conhecimento comum voltado para a compreensão e transformação da realidade existente. Tratase de um procedimento cada vez mais utilizado na avaliação participativa. O objetivo deste artigo é discutir em que medida as bases conceituais da translação do conhecimento podem estar associadas à ideia de 'coletivo de pensamento', desenvolvida por Ludwik Fleck (18961961) na obra 'Gênese e desenvolvimento de um fato científico' (1935).

PALAVRAS-CHAVE Conhecimento. Ciência. Avaliação em saúde.

ABSTRACT In recent years, the modern scientific rationality has been questioned in several ways, among which stands out the translation of knowledge, a research and action method that seeks to encourage the exchange among different knowledge fields, building a common knowledge geared toward understanding and transforming the existing reality. This procedure is increasingly applied in participatory evaluation. The purpose of this article is to discuss to what extent the conceptual bases of knowledge translation may be associated with the idea of 'collective thinking' developed by Ludwik Fleck (1896-1961) in the work 'Genesis and development of a scientific fact' (1935).

KEYWORDS Knowledge. Science. Health evaluation.

1 Fundação Oswaldo Cruz (Fiocruz), Instituto de

Comunicação e Informação

Científica e Tecnologia em Saúde (Icict) - Rio de Janeiro (RJ), Brasil.

leticiatbs@gmail.com

2 Fundação Oswaldo Cruz (Fiocruz), Escola Nacional de Saúde Pública Sergio Arouca (Ensp) - Rio de Janeiro (RJ), Brasil.

andrepereira@ensp.fiocruz.br 


\section{Introdução}

Reflexões sobre o rigor científico e a confiança epistemológica da ciência moderna têm contribuído para colocar em discussão o paradigma científico-social moderno. Constituído a partir da Revolução Científica do século XVI, tal paradigma baseia-se em um modelo de racionalidade em que o conhecimento científico é fruto de uma produção feita por um indivíduo distante e separado de seu objeto (SANTOS, 1988). Nesse paradigma, o mundo é concebido enquanto algo objetivo e independente das pessoas que nele vivem e dele falam. Ele é visto como um ente passível de ser conhecido pelos procedimentos de verificação e mensuração da ciência, considerados objetivos e neutros (VAITSMAN, 1995). Nessa concepção, o enunciado científico deve ser suscetível à prova, podendo ser utilizado como evidência em um debate. Para ser aceito, o argumento cientifico não pode fornecer uma pluralidade de provas inconsistentes ou contraditórias (LYOTARD, 2003). Esse paradigma clássico construiu, ao longo dos anos, um método aceito e reconhecido para a produção do conhecimento (GALLO, 2006).

As demais formas de produção de conhecimento, que não se pautavam por esses princípios epistemológicos e regras metodológicas, foram deixando de ter seu caráter racional reconhecido. A consagração do paradigma científico moderno instaurou, assim, uma dicotomia entre o conhecimento científico e o senso comum - sendo que o segundo passou a ser deslegitimado e invalidado pelo primeiro. A organização dos saberes no paradigma dominante é, em larga medida, eminentemente disciplinar e disciplinada, uma vez que se organiza de forma ostensivamente policiada em relação às fronteiras entre as disciplinas, inibindo possíveis transposições e interações (SANTOS, 2008). Nessa concepção epistemológica fragmentada, o conhecimento científico moderno fechou-se para os demais saberes sobre o mundo, restringindo-se, assim, a limites reducionistas.
No contexto contemporâneo, diferentes campos científicos têm anunciado a exaustão de tal paradigma em apreender a complexidade das realidades concretas da natureza, da história e da cultura humana (ALMEIDA FILHO, 2005). Nessas novas vertentes epistemológicas, muitas vezes denominadas genericamente de 'ciência pós-moderna', o conhecimento científico-natural passou a ser considerado como científico-social (SANTOS, 1988). De acordo com Lyotard (2003), essa forma de ciência 'altera o sentido da palavra conhecimento e diz como pode ocorrer essa mudança. Ela produz não o conhecido, mas o desconhecido'. Nessa perspectiva, o conhecimento não seria produzido a partir do consenso, conforme ocorria na pragmática científica moderna, mas a partir do dissenso sobre aquilo que não se conhece.

As críticas às distinções dicotômicas que caracterizaram a racionalidade moderna ofereceram espaço para a construção de novas vertentes do conhecimento não dualistas, simultaneamente local e total. Afastando-se de sua pretensão iluminista, as novas tendências epistemológicas não se colocariam como capazes de descobrir verdades imanentes, definitivas e incontestáveis. Destituídas de sua objetividade total, elas concebem o fazer científico como um ato criativo de construção, desconstrução e autoconstrução. Elas se dispõem a extinguir as fronteiras entre sujeito e objeto, tornando este uma continuação daquele (SANTOS, 2007). O modo de produzir conhecimento tende a incorporar um grupo amplo e heterogêneo de atores e instituições, valorizando, inclusive, a participação da sociedade civil e o conhecimento dos cidadãos (GIBBONS ET AL., 1994). Essa nova vertente epistemológica dialoga com outros saberes e conhecimentos, deixando-se penetrar por eles (SANTOS, 2008). Eles procuram reabilitar ainda o senso comum, antes considerado falso e ilusório, passando a identificar virtudes nessa forma de conhecimento que enriquecem a relação do homem com o mundo (SANTOS, 2008, 2007). 
O conceito de translação do conhecimento é parte desse novo cenário epistemológico. Isso, porque essa translação visa a facilitar, incentivar e organizar a troca de diversas formas de conhecimento. $\mathrm{O}$ encontro entre o conhecimento científico e o conhecimento fruto da experiência e da vivência no dia a dia permite o desenvolvimento da compreensão e do discernimento entre universos inicialmente estranhos, que, por sua vez, reconfiguram-se gradualmente por meio de interações compartilhadas (CLAVIER ET AL., 2011). Assim, a formação de alianças entre diferentes saberes passaria a ser central para a pesquisa. A translação visa a compreender os acontecimentos que se dão na interface cada vez mais interativa e participativa entre prática e teoria. A literatura dedicada a esse tema enfatiza os processos nos quais o conhecimento é gerado, circula e se transforma na medida em que atravessa de uma esfera social para outra. A translação do conhecimento difere dos movimentos de transferência, uma vez que não estabelece fluxos unidirecionais que partem do pesquisador para o usuário. Ela pretende ser multidirecional, agindo a partir da troca e diálogo entre diferentes saberes, incluindo o científico e o popular (CLAVIER ET AL., 2011; HARTZ ET AL., 2008).

Assim acompanhamos a definição do Canadian Institutes of Health Research, agência federal de fomento à pesquisa canadense sobre translação do conhecimento, quando afirma que ela é um:

processo dinâmico e iterativo que inclui a síntese, a disseminação, o intercâmbio e a aplicação baseada em princípios éticos do conhecimento a fim de incrementar a saúde, prover serviços de saúde e produtos mais efetivos e fortalecer os sistemas de saúde. (CIHR, 2004, P. 2).

A concepção difundida pela Organização Mundial de Saúde (OMS) incorpora o conceito mencionado acima e ressalta que a translação do conhecimento (WHO, 2006, P. 1)

é um paradigma emergente para o aprendizado [a Compreensão] e o agir em prol do preenchimento das lacunas [entre o conhecimento produzido e utilizado]. Enquanto conhecimento é maior que evidências de pesquisa, a translação do conhecimento pode incrementar o poder da evidência científica e a liderança para informar [fundamentar] e transformar políticas e práticas. (WHO, 2006, P. 1).

A translação do conhecimento parece estar consonante com os paradigmas científicos contemporâneos, na medida em que suplanta as fronteiras disciplinares do conhecimento e instiga o diálogo entre diferentes saberes.

Em 1935, Ludwik Fleck lançou o livro 'Gênese e desenvolvimento de um fato científico'. Essa obra apresenta críticas e reflexões sobre o processo de investigação científica que nos parecem centrais para a definição do que venha a ser a translação do conhecimento.

Esse livro contém quatro capítulos e um prefácio. $\mathrm{O}$ autor parte de sua experiência profissional, atendendo pacientes com sífilis, para desenvolver sua reflexão epistemológica. O primeiro capítulo, 'Como surgiu o conceito atual de sífilis', resgata a reflexão histórico-conceitual que se desenvolve nos três capítulos seguintes. $\mathrm{O}$ segundo, 'Consequências para a teoria do conhecimento da história apresentada de um conceito', analisa como o pensamento é, em larga medida, condicionado historicamente. No capítulo, intitulado 'Sobre a reação de Wassermann e sua descoberta', Fleck critica e desmistifica a chamada objetividade científica. No quarto capítulo, 'Aspectos epistemológicos da história da reação de Wassermann', o autor introduz ideias que estão muito em voga atualmente, como aquela que relaciona o conhecimento científico e o saber popular (CURI; SANTOS, 2011).

Esse livro de Fleck (1935) era pouco 
conhecida até que Thomas Kuhn (1998) o mencionou no prefácio de sua obra 'Estrutura das Revoluções Científicas'. Em seu livro, Fleck (2010), colocou em questão o paradigma científico moderno ao apontar os aspectos sociais e históricos que permeiam, moldam e transformam a produção do conhecimento.

Considerando esse contexto, este trabalho discute a seguinte questão: como as bases da translação do conhecimento estão presentes nas ideias propostas por Fleck em 1935?

\section{Fleck e a produção do conhecimento}

Ludwik Fleck (1896-1961) foi um médico bacteriologista e imunologista de origem judaico-polonesa que publicou, em 1935, o livro 'Gênese e desenvolvimento de um fato científico' (2010). Nele, o autor analisa o processo de produção do conhecimento e da formação do 'fato científico' abordando o caso da história da sífilis. Ele destaca as transformações que ocorrem ao longo do tempo e o papel que o contexto histórico exerceu durante esse processo. $\mathrm{O}$ autor apresenta, ainda, reflexões epistemológicas fundamentais para o debate sobre ciência, que anteciparam as noções de alguns pensadores contemporâneos, tais como épistémè, de Foucault (1987), e 'paradigma', de Thomas Kuhn (1998). Essa obra permaneceu no esquecimento até que Kuhn (1998) a resgata e afirma no prefácio de seu livro 'A estrutura das Revoluções Científicas' ao ter 'explorado ao acaso' encontrou:

A monografia quase desconhecida de Ludwik Fleck, 'Entstehung und Entwicklung einer wissenschaftlichen Tatsache', (Basiléia, 1935), um ensaio que antecipa muitas das minhas próprias ideias [...]. O trabalho de Fleck, juntamente com uma observação de outro 'junior fellow', Francis X. Sutton,fez-me compreender que essas ideias podiam necessitar de uma colocação no âmbito da Sociologia da Comunidade Científica. Embora os leitores encontrem poucas referências a qualquer desses trabalhos ou conversas, devo a eles mais do que me seria possível reconstruir ou avaliar neste momento. (KUHN, 1998, P. 11).

Essa redescoberta, feita por Kuhn (1998), serviu para que a obra de Fleck fosse reeditada em diferentes países e passasse a ser lida por diferentes pesquisadores. Atualmente, o pensador polonês é considerado "pioneiro da abordagem sociológica no estudo do conhecimento científico, das comunidades científicas e das práticas dos cientistas" (LÖWY, 1994, P. 236).

O título de sua obra parece ser um indicativo de certa ousadia teórica. Ao utilizar as noções 'gênese' e 'desenvolvimento', Fleck (2010) sugere uma discordância em relação às correntes de pensamento hegemônicas da época (DELIZOICOV ET AL., 2002). Na primeira metade do século XX, o paradigma científico moderno dominava o cenário intelectual. Seguindo esses princípios, o fato científico seria algo dado de modo definitivo, de forma permanente, independente da subjetividade do observador. Nesses termos, admitir uma 'gênese' e um 'desenvolvimento' para o fato científico representaria uma crítica ao paradigma dominante.

Alguns fatores sociais e culturais contribuíram para que Fleck (2010) construísse sua visão sobre o fazer científico. Debruçando-se sobre a história da sífilis, o pensador assinalou que os esforços investigativos e financeiros dispensados ao combate à doença não estiveram ligados tão somente a fatores objetivos ou científicos. A sífilis, também chamada de 'flagelo carnal' ou 'sangue corrompido', era uma doença percebida com forte cunho moral e religioso.

Para Fleck (2010):

Contentar-se com a explicação genérica, no entanto, de que o conceito de sífilis seria inatingível, sem analisar o contexto histórico específico, seria um erro grosseiro. Deve-se 
ainda investigar as leis desse contexto e detectar o impacto das forças sociais no pensamento. (FLECK, 2010, P. 64).

Para 'detectar o impacto das forças sociais no pensamento', Fleck (2010) destacou que o estigma existente no pensamento social sobre a sífilis, naquela época, exerceu papel decisivo no desenvolvimento de pesquisas sobre essa doença, em detrimento da tuberculose que tinha maior letalidade. Fleck (2010) observa que as supostas escolhas epistemológicas não seriam processos tão somente individuais, mas apresentariam uma dependência social-cultural, assim como estariam permeadas por leis específicas que governariam o desenvolvimento de suas ideias.

Outro aspecto presente na obra de Fleck (2010) está relacionado com sua crítica à tradicional relação dual entre sujeito e objeto, concebida como se fosse um processo individual de consciência em si.

Para o autor:

A teoria comparada do conhecimento não deve considerar o processo do conhecimento como uma relação binária entre sujeito e objeto, entre ator do conhecimento e algo a ser conhecido. [...] As relações históricas e estilísticas dentro do saber comprovam a existência de uma interação entre objeto e o processo de conhecimento. (FLECK, 2010, P. 81).

Fleck (2010) sugere que a cognição se apresenta como resultado de uma atividade social que envolve o indivíduo, o coletivo e a realidade a ser conhecida. Segundo o autor,

o indivíduo nunca, ou quase nunca, está consciente do estilo de pensamento coletivo que, quase sempre, exerce uma força coercitiva em seu pensamento e contra a qual qualquer contradição é simplesmente impensável. (FLECK, 2010, P. 84).

No seu entender, há uma interação entre aquilo que se sabe e a atividade cognitiva, uma vez que o já conhecido influencia os métodos de cognição, enquanto estes, por sua vez, renovam, expandem ou atualizam o conhecimento.

Cabe ressaltar que tais movimentos se configurariam dentro daquilo que o autor denomina "coletivo de pensamento" (FLECK, 2010, P. 82). Esse conceito se refere a uma comunidade de pessoas que trocam mutuamente ideias ou estabelecem uma interação intelectual e, por esta razão, desenvolvem um estilo de pensamento coletivo. Fleck (2010, P. 85) afirma que

o processo de conhecimento representa a atividade humana que mais depende das condições sociais, e o conhecimento é o produto social por excelência.

Tal estilo não engloba apenas o conjunto de pressupostos presentes no estoque de conhecimento específico do grupo, mas, também, o conjunto de métodos e ferramentas a partir do qual é possível analisar as evidências e verificar os resultados. Desse modo, Fleck (2010) delineia a ciência como um processo de construção eminentemente coletivo.

Nas suas palavras:

Se definirmos o 'Coletivo de Pensamento' como a comunidade das pessoas que trocam pensamentos ou se encontram numa situação de influência recíproca de pensamentos, temos, em cada uma dessas pessoas um portador do desenvolvimento histórico de uma área de pensamento, de um determinado estado do saber e da cultura, ou seja, de um estilo específico de pensamento. (FLECK, 2010, P. 82).

Além disso, ele sugere que o conhecimento científico não seja visto como algo isolado do grupo de pessoas que o constrói ou das condições em que é produzido (LÖWY, 1994). Em uma de suas passagens Fleck (2010) afirma:

Permitam-se uma comparação um tanto trivial: um indivíduo pode ser comparado a um jogador de futebol, o coletivo de pensamento 
ao time treinado para colaborar e o conhecimento ao andamento do jogo. Será que o andamento só pode ser analisado a partir do chute individual? Perder-se-ia todo o sentido do jogo. (FLECK, 2010, P. 88).

Isso não quer dizer que o autor descarte o papel do indivíduo. No seu entender:

Sem dúvida, a história da ciência registra também façanhas independentes e pessoais, por assim dizer. [...] Não se poderia imaginar um Napoleão antes da Revolução Francesa. Sem o momento social adequado, ambos (refere-se também a Vesalius) não teriam alcançado sua grandeza. [...] Não se pretende dizer que o indivíduo não teria importância como fator do conhecimento. (FLECK, 2010, P. 89).

Na perspectiva do pensador polonês, não devem ser atribuídos aos conceitos e teorias características como certo ou o errado. Para ele, os conceitos e teorias não são estanques, definitivos ou essenciais, mas variam conforme o contexto em que se encontram. De acordo com Fleck (2010), é impossível determinar se a teoria atomista desenvolvida na Grécia Antiga é ou não correta. Sua análise pressupõe que sejam levadas em consideração as especificidades daquele contexto histórico e o estilo de pensamento a que os produtores daquele conhecimento pertenciam. Para o autor,

de um modo geral, a afirmação, implicitamente contida naquela opinião de que se podia aplicar às ideias antigas e confusas as categorias da verdade e da inverdade, é equivocada. (FLECK, 2010, P. 67).

Em outro trecho afirma: "Qualquer teoria do conhecimento que não leva em conta esse condicionamento social de todo o conhecimento é uma brincadeira" (FLECK, 2010, P. 86).

Considerando que a atividade científica é dotada de componentes históricos, sociais e culturais, Fleck (2010) admite que a explicação científica só pode sobreviver e se desenvolver se estiver em conformidade com o estilo de pensamento prevalente em seu tempo. Além disso, ela só pode ser compreendida a partir dele. No seu entender, os fatos científicos sobre os quais tais atividades se debruçam não estão dados ou são dotados de uma essência objetiva, mas conformados, em última instância, pelo estilo de pensamento em voga.

Fleck (2010) sugere, no início dos anos 1930, de modo inovador, que a ciência não é formada por processos lineares, monolíticos e uni causais. Pelo contrário, ela é um fenômeno social e cultural, fruto da interação entre diferentes indivíduos. Para o autor, ela se configura a partir da troca mútua, dos embates e das associações.

Bruno Latour, no posfácio à edição francesa da obra de Ludwik Fleck, afirma que:

O 'pensamento coletivo' não é apenas uma prefiguração estranha do celebre 'paradigma'. Nada seria mais injusto. Longe de ser um precursor ultrapassado, Fleck continua sendo um pioneiro mais adiante do estágio atual de nossos conhecimentos. (LATOUR, 2005B, P. 99 FLECK 1, TRADUÇ̃̃O NOSSA).

Explorando a obra do teórico polonês, podemos observar que muitas de suas discussões dialogam com muitos questionamentos contemporâneos, tais como as questões do estatuto de verdade absoluta do conhecimento científico, da dicotomia entre sujeito e objeto, da neutralidade do pesquisador e da objetividade da ciência. Esses embates filosóficos foram, portanto, precursores das críticas à que a racionalidade científica moderna tem sido submetida nos últimos anos.

Analisando os pressupostos da translação do conhecimento, acreditamos ser possível traçar um paralelo entre esse conceito e as ideias elaboradas por Ludwig Fleck há quase um século. Essa aproximação nos parece possível, sobretudo a partir as noções de troca, interação e coletivo na produção do conhecimento. 


\section{Translação do conhecimento: alguns apontamentos}

O conhecimento produzido pela pesquisa, quando amplamente disseminado, pode se tornar um bem público global, auxiliando na formulação de políticas, ações e serviços de atendimento ao público, de forma individual ou coletiva. Assim, a aplicação do conhecimento pode ser considerada estratégica para a transformação das condições de vida do cidadão e redução das iniquidades sociais (PANG ET AL., 2003; STRAUS ET AL., 2009). Ainda que possa ser considerada recomendável, tal abordagem ainda não se consolidou plenamente, uma vez que muitas evidências científicas tendem a não ser incorporadas à prática. Mediante o reconhecimento desse problema, é cada vez maior a preocupação em encontrar formas de reduzir a lacuna entre conhecimento e ação - denominada em inglês como knowledge-to-action gap (GRAHAM ET AL., 2006).

Graham et al. (2006) ressaltam que há diferentes termos para descrever processos de conhecimento para ação - ora utilizados como sinônimos, ora utilizados referindo-se a ações de estratégias específicas. Segundo Straus et al. (2009), as expressões implementation science e research utilization são mais comuns na Europa. Nos Estados Unidos, são mais frequentes as expressões research use, uptake, transferência, disseminação e difusão de conhecimento.

A translação do conhecimento integra essa nova tradição epistemológica. Ela é mais utilizada no Canadá: sua adoção proeminente deve-se à incorporação da 'translação do conhecimento' em pesquisas apoiadas pela agência federal Canadian Institutes of Health Research (CIHR), responsável pelo financiamento de investigações em saúde naquele País (GRAHAm ET AL., 2006). Esse termo tem sido historicamente utilizado para descrever uma série de atividades que visam a preencher a lacuna entre conhecimento e prática.

No Canadá, a translação do conhecimento auxilia o processo de tomada de decisão (GRAHAM ET AL., 2007). O principal objetivo da translação do conhecimento naquele País é aperfeiçoar o sistema de saúde e melhorar o bem-estar dos indivíduos, a partir de um processo dinâmico de síntese, disseminação, troca e aplicação ética do conhecimento. Para tanto, é constituído um complexo sistema de interações entre pesquisadores e usuários (CIHR, 2014).

Para Clavier et al. (2011), o conceito de translação pode ser explorado a partir da literatura da área, associada à 'sociologia dos atores intermediários' e à 'teoria ator-rede', desenvolvida por Latour (2005A). Segundo esses autores, a translação na pesquisa participativa em saúde se configura como um processo inovador e multifacetado que possibilita trocas multidirecionais e coconstrução de conhecimento entre diferentes atores. Ela é constituída por três tipos de prática diferentes: as 'cognitivas', que se referem ao conteúdo das parcerias, contribuindo para a organização da produção, circulação e translação do conhecimento em múltiplas direções; as 'estratégicas', que abrangem as atividades, ferramentas e competências mobilizadas para estimular e manter o interesse na pesquisa; e as 'logísticas', que envolvem a coordenação das tarefas capazes de estabelecer as condições para parceria (CLAVIER ET AL., 2011).

Cabe ressaltar que a translação se encontra estreitamente atrelada à noção de rede, uma vez que ela pode ser vista como um complexo de operações de translação, por meio das quais são produzidos conhecimentos e práticas inovadoras (MANTOURA ET AL., 2007). Na 'teoria ator-rede', desenvolvida por Latour (2005), o conceito translação não remete a uma relação de causalidade, mas a outra que induz dois mediadores à coexistência: não se daria, portanto, a partir de processos causais lineares e unidirecionais, 
mas a partir da ação conjunta, da ou na interação. Segundo Callon (1986), ela pode se desenvolver ao longo de quatro momentos no processo de formação das redes. Primeiramente, há a 'problematização', na qual um sistema de alianças ou associações é formado entre as entidades e atores envolvidos, visando a estabelecer um acordo sobre o problema de uma dada situação, considerado seus diferentes interesses, posições sociais, valores e experiências. Posteriormente, dá-se a atração de interesses, ou interessement. Nesse momento, observa-se um conjunto de ações em que uma entidade alinha os interesses e identidades existentes na rede, definindo como cada um pode contribuir para a solução do problema identificado. Em seguida, ocorre o 'recrutamento'. Nele são definidos e atribuídos os papéis aos 'actantes'. Finalmente, há a 'mobilização', quando são determinados os métodos a serem aplicados.

A translação desenvolve-se em formas reticulares, abertas, flexíveis e dinâmicas. Assim, ela facilita a troca de diferentes conhecimentos e saberes, possibilitando tanto a construção de novas identidades e interesses como o desenvolvimento de uma compreensão compartilhada entre universos inicialmente diferentes (MANTOURA ET AL., 2007).

Nessa perspectiva, podemos observar que o atual conceito de translação de conhecimento foi construído a partir de quadros teóricos característicos do final do século XX e início do século XXI. Eles parecem dialogar, de maneira geral, com as críticas ao paradigma científico moderno construído a partir da Revolução Científica do século XVI.

O desafio deste artigo é sugerir que as proposições da translação de conhecimento remontam às ideias de um debate pouco conhecido, travado na década de 1930, por um médico cuja importância na sociologia da ciência foi recentemente reconhecida: Ludwik Fleck (1896-1961).

\section{Translação do conhecimento e Fleck: entre o presente e o passado}

Conforme ressaltado anteriormente, para Fleck (2010), a cognição não é um processo individual, mas está atravessado por uma dimensão coletiva: o conhecimento é produzido de acordo com as condições históricas, sociais e culturais em que se encontra e a partir de trocas mútuas entre o indivíduo, o coletivo e a realidade. Em vez de ocuparem uma posição necessariamente antagônica, ciência e o senso comum, por vezes, imbricam-se.

Segundo o autor:

Os três fatores que participam do processo de conhecimento, a saber, o indivíduo, o coletivo e a realidade objetiva (aquilo que é para ser conhecido), não são seres metafísicos: também são passíveis de análise, isto é, há ainda outras relações entre eles. (FLECK, 2010, P. 83).

O conceito de translação do conhecimento parece seguir a mesma perspectiva. Retomando a definição de Clavier et al. (2011), a translação implica trocas multidirecionais e a coconstrução do conhecimento entre diferentes atores, pressupondo práticas que circulem diversos saberes.

Sobre o caso da sífilis, Fleck declara:

Partindo de uma experiência de vários anos no setor venéreo [...] cheguei à convicção de que, mesmo o pesquisador moderno, munido de todo equipamento intelectual, nunca chegaria a distinguir todos esses quadros clínicos. [...] Somente a comunidade organizada de pesquisadores, apoiada no saber popular e trabalhando durante algumas gerações, consegue alcançar esse objetivo [...]. (FLECK, 2010, P. 63).

Outro aspecto que aproxima a translação do conhecimento dos postulados de Fleck (2010) está associado ao fato de ambos os quadros teóricos conceberem o conhecimento 
como algo que guarda relações com o passado e que não se constrói em um processo estático e linear. Segundo Fleck (2010), o conhecimento não é espontaneamente gerado, mas produzido e transformado de acordo com as ideias predecessoras que o formaram, com aquilo que já se sabe e com o estilo de pensamento predominante. Para ele:

[...] na reação de Wassermann [...] é a expressão científica moderna e uma pré-ideia existente há séculos que contribui para a construção do conceito de sífilis. (FLECK, 2010, P. 65).

Assim, para Fleck (2010, P. 81):

[...] Algo já conhecido influencia a maneira do conhecimento novo; o processo do conhecimento amplia, renova e refresca o sentido do conhecimento.

Para Mantoura et al. (2007), na translação do conhecimento:

Os programas de ação são inevitavelmente instáveis e frequentemente revisados na medida em que o conhecimento é produzido e combinado com os resultados do passado e reconstrução das alianças. (MANTOURA ET AL., 2007, P. 442, TRADUÇÃO NOSSA).

Conforme recebem novos fatos e informações, os indivíduos reorganizam aquilo que já sabem, produzindo novos conhecimentos por meio de interações, adaptações e negociações.

Em Fleck (2010), a dimensão coletiva e social do conhecimento contribui para que sua construção não ocorra de forma harmoniosa. As ideias, quando são capazes de formar um sistema de opinião estruturalmente completo, fechado e detalhado, apresentam resistência àquilo que a contradiz. Ao deparar-se com novos conceitos, a tenacidade de tal sistema passa por diferentes estágios. Por um lado, as contradições à sua estrutura parecem inimagináveis. Por outro, os pressupostos que nele não se encaixam, se tornam invisíveis ou são mantidos em segredo. Muitas vezes, esforços são feitos para explicar as exceções, de modo que o conhecimento não seja invalidado. Apesar da legitimidade das perspectivas divergentes, uma versão ou visão tende a ser considerada como aquela que corrobora e dá substância às visões atuais.

Segundo Fleck:

A fecundidade da teoria do coletivo de pensamento se evidencia justamente na possibilidade de comparar os modos de pensar primitivo, arcaico, infantil e psicótico e de analisá-los de maneira coerente. Em última instância, isso vale também para o modo de pensar de um povo, de uma classe, de um grupo qualquer. (FLECK, 2010, P. 94).

Analisando o caso da sífilis, o autor aponta que a persistência prolongada do conceito de 'flagelo carnal' contra novas noções não seria decorrente de uma simples passividade ou desconfiança de novas ideias, mas da tenacidade do sistema de opinião no qual se encontrava. Desse modo, podemos observar que, para Fleck (2010), a produção de conhecimento não possui apenas acordos e consentimentos, mas também oposições, embates e resistências. Segundo ele:

uma vez formado, um sistema de opinião elaborado e fechado, constituído de muitos detaIhes e relações, persiste continuamente diante de tudo que o contradiga. (FLECK, 2010, P. 69).

No conceito de translação, podemos notar uma abordagem similar acerca do conhecimento. De acordo com Mantoura et al. (2007), a produção do conhecimento se conforma no interior de alianças de aprendizagem, cuja natureza pode influenciar seu processo e resultados. Caso sejam forjadas a partir da confiança, tais alianças organizam a produção de conhecimento e a aprendizagem com maior sinergia entre os interesses dos participantes. 
Assim, as contribuições dos indivíduos são facilitadas, construindo processos de cooperação e resolução conjunta de problemas capazes de neutralizar e transformar diferenças de poder e dinâmicas de controle. Entretanto, se forem forjadas por oportunismo, as mesmas relações tendem a favorecer interesses individuais em detrimento do coletivo, incentivando a barganha e o conflito. Mantoura et al. (2007) ressaltam que as alianças estratégicas são instáveis. Elas estão sujeitas a modificações, visto que o comportamento dos membros é geralmente incerto. A cooperação mútua não é automática nem previsível ou definitiva. Os atores que antes formavam uma aliança de cooperação podem, por diferentes fatores, transmutar sua relação de confiança para outra oportunista ou reativa.

Nessa perspectiva, nota-se que tanto no conceito de translação do conhecimento como no 'coletivo de pensamento', de Fleck (2010), a produção do conhecimento não é vista como algo asséptico ou neutro, mas pleno de conflitos, concessões e interesses em disputa.

Também nos parece possível aproximar o conceito de 'coletivo de pensamento', elaborado por Fleck (2010), e a noção de rede presente na translação do conhecimento.

Para o autor:

Quando se olha o lado formal do universo cientifico, sua estrutura social é óbvia: Vemos um trabalho coletivo organizado com divisão de trabalho, colaboração, trabalhos preparativos, assistência técnica, troca de ideias, polemicas etc. [...] Há uma hierarquia científica, grupos, adeptos e adversários, sociedades e congressos, periódicos, instituições de intercâmbio etc. (FLECK, 2010, P. 85).

Como podemos perceber, o trabalho científico para Fleck (2010) apresenta-se como um trabalho coletivo socialmente estruturado. Para ele, o conhecimento não pode ser concebido fora do coletivo de pensamento que o formula, isto é, fora do grupo de pessoas que, a partir de um estilo de pensamento em comum, realiza esforços conjuntos para desenvolvê-lo. De acordo com Fleck (2010), um coletivo de pensamento existe quando duas ou mais pessoas trocam ideias, seja em um laboratório ou em uma conversa informal estimulante. $\mathrm{O}$ conhecimento coletivo é construído na medida em que aumentam as interações, os entendimentos e desentendimentos entre os atores envolvidos. Caso outras pessoas se juntem a esse processo de troca, um novo coletivo emerge. $\mathrm{O}$ autor admite que um mesmo indivíduo possa pertencer simultaneamente a diferentes coletivos de pensamento. Para o autor,

um pensamento coletivo, por analogia, é composto por diferentes indivíduos e também tem as suas regras especiais de comportamento e sua forma psicológica particular. (2010, P. 44)

No conceito de translação, a coletividade é a base central para a produção do conhecimento. Ao criar conexões multidirecionais entre diferentes entidades a partir de formas reticulares, a translação conforma uma coconstrução do conhecimento em fluxos multidirecionais, envolvendo atores e espaço não necessariamente acadêmicos (CLAVIER ET AL., 2011).

Trançando um paralelo entre os parâmetros da translação do conhecimento e o 'coletivo de pensamento' de Fleck (2010), podemos dizer ambos não se constroem apenas no meio científico, mas a partir da interação e da conexão entre diferentes saberes. Não há um indivíduo a quem possa ser atribuída a ideia original, tampouco outro que seja apenas seu receptor ou transportador. Nos dois casos, há um esforço em empreender um movimento conjunto onde todos participem e contribuam no processo de construção do conhecimento.

Nos dois casos, parece-nos impossível conceber a produção do conhecimento longe de sua dimensão sociocultural, uma vez que o conhecimento é desenvolvido a partir da interação, da associação e da troca entre diferentes indivíduos, portadores de diferentes saberes e experiências. 


\section{Considerações finais}

Nas últimas décadas, algumas críticas têm sido elaboradas acerca do processo de construção do conhecimento científico formal hegemônico. Está sendo questionada a falta de interação entre o saber acadêmico e outros saberes e seu caráter eminentemente objetivo. A translação do conhecimento parece ser característica desse cenário de críticas aos postulados tradicionais do fazer científico e da relação entre o observador e seu objeto observado. Ela desloca movimentos, lugares e espaços tradicionais da pesquisa científica, incentivando a troca múltipla entre diversos atores a fim de construir coletivamente um conhecimento capaz de ser aplicado na prática e utilizado no processo de tomada de decisão.

Recentemente, as ideias e elaborações realizadas Ludwik Fleck (1896-1961), um pesquisador ainda pouco conhecido e debatido no campo da epistemologia, têm sido redescobertas e debatidas. A tradução para português da obra de Fleck, 'Gênese e desenvolvimento de um fato científico' (1935), contribuiu, em 2010, para que o pensamento do autor estivesse mais acessível para docentes e discentes brasileiros. No campo acadêmico nacional, além de resenhas sobre o livro (MAIA, 2011; CARNEIRO, 2015), há trabalhos que abordam a teoria do conhecimento do pensador polonês, atentando para suas contribuições epistemológicas na reflexão sobre o conhecimento científico e para seu potencial na investigação de questões relacionadas ao ensino (DELIzoIcov ET AL., 2002; PfUetZenReiter, 2002). Há também trabalhos que recorrem à perspectiva de Fleck (2010) para analisar consensos de especialistas sobre classificações médicas como fenômeno sociocultural (MACHADO, 2008), enquanto outros a utilizam para pensar a questão da interdisciplinaridade na saúde (MATOS; GONÇALVES; RAMOS, 2005).

Este artigo teve como objetivo contribuir para o debate sobre Ludwik Fleck e suas elaborações teóricas, tratando sobre um objeto ainda não analisado na produção acadêmica até o momento: as possíveis relações entre o pensamento de Fleck e o conceito de translação do conhecimento.

Embora o conceito de translação seja recente, valendo-se de teorias e pensamentos sociológicos contemporâneos, sugerimos, ao longo deste artigo, que algumas de suas principais noções dialoguem com ideias elaboradas há quase um século por Fleck (2010). Na translação do conhecimento, o caráter coletivo, multidirecional, conflituoso e diversificado do conhecimento parece remeter ao debate elaborado pelo pensador polonês. Na década de 1930, ele já apontava a dimensão social, cultural e histórica do processo de construção do conhecimento. Ele identificava os embates e negociações que atravessavam a produção do conhecimento e moldavam seus fatos científicos.

Ao observar as aproximações entre ideias, conceitos e práticas tão distantes temporalmente, recorremos a Fleck (2010, P. 61), quando afirma: "não existe geração espontânea de conceitos; eles são, por assim dizer, determinados por seus ancestrais".

\section{Colaboradores}

Os autores participaram de todas as etapas da construção deste artigo, i.e., concepção, planejamento, análise e interpretação dos dados; elaboração do rascunho e revisão crítica do conteúdo; e aprovação da versão final do manuscrito.

\section{Agradecimentos}

Agradecemos à professora Elizabeth Moreira dos Santos por nos ter sugerido a conexão entre as ideias de Fleck e a translação do conhecimento. 


\section{Referências}

ALMEIDA FILHO, N. Transdisciplinaridade e o paradigma pós-disciplinar na saúde. Saúde soc., São Paulo, v. 14, n. 3, p. 30-50, dez. 2005.

CALLON, M. Some elements of a sociology of translation: domestication of the scallops and the fishermen of St Brieuc Bay. In: LAW, J. Power, action and belief: a new sociology of knowledge? Londres: Routledge, 1986, p. 196-223.

CANADIAN INSTITUTES OF HEALTH RESEARCH (CIHR). Knowledge Translation Strategy 2004-2009: Innovation in Action. Ottawa: CIHR, 2004. Disponível em: <http://www.cihr-irsc.gc.ca/e/26574.html>. Acesso em: 6 set. 2016

\section{CANADIAN INSTITUTES OF HEALTH RESERCH} (CIHR). Knowledge Translation - Definition. 2014. Disponível em: < http://www.cihr-irsc.gc.ca/e/29418. html\#2>. Acesso em: 22 ago. 2015.

CARNEIRO, J. A. Gênese e recepção do projeto epistemológico de Ludwik Fleck. Sci. stud., São Paulo, v. 13 , n. 3, p. $695-705$, set. 2015

CLAVIER, C. et al. A theory-based model of translation practices in public health participatory research. Sociology of Health \& Illness, Bethesda, v. 34, n. 5, p. 791-805, set. 2011

CURI, L. M.; SANTOS, R. C. Ludwik Fleck e a análise sociocultural da(s) ciência(s). Hist. cienc. SaúdeManguinhos, Rio de Janeiro, v. 18, n. 4, p. 1169-1173, dez. 2011.

DELIZOICOV, D. et al. Sociogênese do conhecimento e pesquisa em ensino: contribuições a partir do referencial fleckiano. Cad. Bras. Ens. Fís., Florianópolis, v. 19, n. esp., p. 52-69, jun. 2002.

FLECK, L. Gênese e desenvolvimento de um fato científico. Belo Horizonte: Fabrefactum, 2010.

FOUCAULT, M. A arquelogia do saber. 3 ed. Rio de Janeiro: Forense Universitária, 1987.
GALLO, S. Modernidade/pós-modernidade: tensões e repercussões na produção de conhecimento em educação. Educ. Pesqui., São Paulo, v. 32, n. 3, p. 551-565, dez. 2006.

GIBBONS, M. et al. The new production of knowledge: the dynamics of science and research in contemporary societies. Sage: Londres, 1994.

GRAHAM, I. et al. Lost in knowledge translation: time for a map? J. Contin. Educ. Health. Prof., New York, v. 26, p. 13-24, dez. 2006.

GRAHAM, I. et al. Some theoretical underpinnings of knowledge translation. Acad. Emerg. Med., Philadelphia, v. 11, n. 14, p. 936-941, nov. 2007.

HARTZ, Z. et al. From knowledge to action: challenges and opportunities for increasing the use of evaluation in health promotion policies and practices. In: POTVIN, L.; MCQUEEN, D. (Org.). Health promotion evaluation practices in the Americas: values and research. New York: Springer, 2008, p. 101-120.

KUHN, T. A estrutura das revoluções científicas. São Paulo: Perspectiva, 1998.

LATOUR, B. Reassembling the social: an introduction to actor-network-theory. Oxford: Oxford University, 2005a.

Transmettre la sphilis: partagerl'objectivité. In: FLECK, L. Genèse et développement d'un fait scientifique. Paris: Les Belles Lettres, 2005b, p. 99 Fleck 1-5. Disponível em: <http://www.bruno-latour.fr/sites/ default/files/P-99\%20Fleck-postface.pdf $>$. Acesso em: 9 nov. 2016.

LÖWY, I. Fleck e a historiografia recente da pesquisa biomédica. In: PORTOCARRERO, V. (Org.). Filosofia, história e sociologia das ciências I: abordagens contemporâneas. Rio de Janeiro: Fiocruz, 1994. p. 233-249.

LYOTARD, J. A condição pós-moderna. 3. ed. Lisboa: Gradiva, 2003. 
MACHADO, P. S. Intersexualidade e o consenso de 'Chicago': as vicissitudes da nomenclatura e suas implicações regulatórias. Rev. bras. ciênc. soc., São Paulo, v. 4, n. esp., p. 109-124, out. 2008.

MAIA, C. A. Uma chave de leitura de Fleck para a pesquisa. Hist. cienc. saúde-Manguinhos, Rio de Janeiro, v. 18, n. 4, p. 1174-1179, dez. 2011.

MANTOURA P. et al. Participatory research in public health: creating innovative alliances for health. Health Et Place, Oxford, v. 13, n. 2, p. 440-451, jun. 2007.

MATOS, E.; GONCALVES, J. R.; RAMOS, F. R. S. A epistemologia de Ludwick Fleck: subsídios para a prática interdisciplinar em saúde. Texto contexto enferm., Florianópolis, v. 14, n. 3, p. 383-390, set. 2005.

PANG T. et al. Knowledge for better health: a conceptual framework and foundation for health research systems. Bulletin of the World Health Organization, Geneva, v. 11, n. 81, p. 815-820, jan. 2003.

PFUETZENREITER, M. R. A epistemologia de Ludwik Fleck como referencial para a pesquisa no ensino na área de saúde. Ciênc. educ. (Bauru), Bauru, v. 8, n. 2, p. 147-159, 2002.

SANTOS, B. S. Um discurso sobre as ciências na transição para uma ciência pós-moderna. Estud. av., São Paulo, v. 2, n. 2, p. 46-71, ago. 1988.
Para além do pensamento abissal: das linhas globais a uma ecologia de saberes. Novos estud. -

CEBRAP, v. 79, p. 71-94, nov. 2007.

Um discurso sobre as ciências. São Paulo:

Cortez, 2008.

STRAUS, S. E. et al. Defining knowledge translation. Canadian Medical Association Journal, Ottawa, v. 181, n. 3-4, p. 165-181, jul. 2009.

VAITSMAN, J. Subjetividade e paradigma de conhecimento. Boletim técnico do SENAC, v. 21, n. 2, maio/ago. 1995. Disponível em: <http:// oceanusacademico.blogspot.com.br/2011/04/oparadigma-da-subjetividade.html>. Acesso em: 8 nov. 2016.

\section{WORLD HEALTH ORGANIZATION (WHO),}

Bridging the "Know -Do" Gap: Meeting on Knowledge Translation in Global Health. Geneva: WHO, 2006.

Recebido para publicação em abril de 2016

Versão final em outubro de 2016

Conflito de interesses: inexistente

Suporte financeiro: não houve 